\title{
CUESTIONES LINGÜÍSTICAS SOBRE EL TEXTO ORAL
}

VIDAL LAMÍQUIZ

UNED

\section{HACIA EL TEXTO ORAL}

Texto, en su sentido etimológico, de textus, equivale a entramado o urdimbre, disposición de los hilos de una tela. Continuando en la imagen metafórica, el texto lingüístico supone un tejido de palabras entramadas, unidas en un entrelazamiento de disposición regulada, que proporciona una consistencia de totalidad comunicativa.

El texto es, pues, un resultado lingüístico plasmado como realidad enunciativa, actualizada y hecha concreta, capaz de ser contemplada empíricamente en dos aspectos concomitantes y mutuamente dependientes que se prestan a experimentación: la realidad observable de su sucesividad sintagmática discursiva y la realidad interpretable de su contenido comunicativo.

Es conveniente adoptar un criterio semiótico que, en una mayor complejidad de factores cooperantes hacia la información comunicativa global del mensaje, supera la sola especulación lógica del sistema lingüístico. Así, el texto es un resultado enunciativo que el hablante ofrece como conjunto comunicativo para ciertos oyentes, uno o varios o todos los posibles interesados.

Por inercia de nuestra tradición social escrita, de premisas apoyadas eminentemente en lo literario, se ha considerado el texto escrito como texto por an- 
tonomasia. Y, como tal texto escrito, se le concede automáticamente la característica de perfección, con modelos de referencia fundamentados en una permanencia clásica.

Basta consultar el Diccionario. El DRAE (1984) en su primera acepción de texto es «lo dicho o escrito por un autor»; en su segunda acepción es «pasaje citado de una obra literaria»; dejando la tercera, ya en sublimación sacralizada, «sentencia de la Sagrada Escritura», la cuarta amplía: «todo lo que se dice en el cuerpo de la obra manuscrita o impresa». Reuniendo esos rasgos definidores, la sensación caracterizante de un texto es, en consecuencia, lo producido por un autor, en una obra literaria, manuscrita o impresa.

La quinta acepción de texto que ofrece el DRAE, supone una referencia más bien técnica, situada en el ámbito de quienes se preocupan por la comunicación lingüística: «enunciado o conjunto de enunciados orales o escritos que el lingüista somete a estudio». Pero esta acepción, al señalar indiscriminadamente que los textos son «orales o escritos", introduce por primera vez el texto oral y, de manera subrepticia, por la lógica de una implícita coherencia, induce a una capciosa generalización errónea si se aplican al texto oral los criterios definitorios que rigen para el texto escrito y literario, precisados en las anteriores acepciones.

De no tener en cuenta ese error de atribución, generalizante por falsa inclusión, fácilmente se cae en la dicotomía tópica: frente al texto escrito, literario y modélico, se encuentra el texto oral, improvisado, descuidado, irreflexivo, desacertado, repleto de frases abortadas, incompleto, plagado de incorrecciones $e$, incluso, connotado como basto, vulgar e inculto. De ahí la imprescindible escolarización a fin de que, se ha dicho con pomposa vaciedad, «las personas recuperen la dignidad» (EL PAIS, 30-12-92). Y quizás también con la utópica pretensión de que el escolarizado, iya dignificado!, alcance el ilusorio ideal de «hablar como un libro".

\section{CRITERIOS DE ANÁLISIS Y DE VALORIZACIÓN}

Procuremos liberar nuestra actitud lingüística de esos desorientadores apriorismos que, de manera tan automática y sin vacilación previa, aplican al texto oral las premisas tradicionales del texto escrito.

Para ello, y trazando el necesario esquema mental, insistamos en el hecho de que la diferencia textual entre lo escrito y lo oral se apoya en la manera enunciativa de realización: en el texto oral la comunicación enunciativa se ex- 
terioriza por medio de los naturales sonidos vocálicos, producidos directamente en pertinencia fonologica, con la ayuda del aparato fonador de que está dotada la persona humana. Mientras que el texto escrito manifiesta la comunicación indirectamente o de manera sucedánea a través de los grafemas consensuados en la tradición cultural histórica. Son, pues, dos modos o maneras de exteriorización linguística claramente distintos.

En la observación analítica de cada uno de esos dos tipos de productos se instaura una gradación valorativa que se vale, a su vez, de criterios también diferentes. En el resultado enunciativo oral opera el criterio sociolingüistico. Este criterio organiza una escala de valores en función del grado de prestigio social que la actitud de los miembros de la comunidad hablante concede a cada realización oral concreta. Esta gama valorativa de aceptación social va desde lo oral culto hasta lo oral popular y se cuantifica por medio de la llamada «regla variable» que mide el grado de aceptación sociolingüística de cada comportamiento comunicativo oral.

En la valoración del resultado enunciativo escrito funciona un criterio estilístico. La crítica literaria propone un conjunto de premisas que establecen, por su parte, una gama valorativa de apreciación de su uso artístico (R. Senabre, 1992: 3-4) que va desde lo escrito literario hasta lo escrito coloquial y señala el grado de literariedad de cada texto.

Así, exponiendo en un sencillo esquema visual esta doble clasificación, podríamos indicar:

\begin{tabular}{|c|cc|}
\hline \multirow{7}{*}{ TEXTO } & $\begin{array}{c}\text { Manera enunciativa } \\
\text { de realización } \\
\text { exteriorizante }\end{array}$ & Valoración gradual \\
\cline { 2 - 3 } & ESCRITO & $\begin{array}{c}\text { Literario } \\
\text { Criterio estilístico } \\
\text { Literariedad } \\
\text { Coloquial }\end{array}$ \\
\cline { 2 - 3 } & ORAL & $\begin{array}{c}\text { Culto } \\
\text { Criterio sociolingǘstico } \\
\text { Prestigio social }\end{array}$ \\
& & Popular \\
\hline
\end{tabular}


Desde luego, es evidente que el texto oral, al igual que el texto escrito, puede ser objeto de una valoración estilística (por ejemplo, en A. Narbona, 1986; así como 1988; recogidos ambos en 1989: 171-203 y 149-169). Porque el enunciado oral cotidiano, aunque no necesariamente sea siempre coloquial, a causa de su habitual espontaneidad interlocutiva y su práctica finalidad comunicativa se presta más fácilmente a que lo sea. $Y$, en este enfoque, con un criterio literario no es nada difícil encontrar textos orales coloquiales lo mismo que textos escritos coloquiales (cf. W. Beinhauer, 1978).

Mas, a veces se tiende a identificar lo oral con lo coloquial o, sin llegar a tanto, a mezclar indiferenciadamente ambos fenómenos (por ejemplo en A. M." Vigara, 1992: 13, 15, 16...). Teniendo en cuenta nuestra sistematización, puede resultar bastante desorientadora, si no errónea, la mezcla de criterios. Porque recordemos que la oralidad es una manera exteriorizante de realización textual, patentemente clasificatoria. Mientras que lo coloquial es un rasgo de estilo $\mathrm{y}$, en cuanto tal, gradual y de límites confusos, dependiente de apreciaciones subjetivas objetivables acerca de la modalidad literaria de un texto. Y es bien conocida la incongruencia que supone el hecho de contraponer en el mismo nivel de reflexión dos ordenes distintos de criterio analítico.

En conclusión, tanto el texto escrito como el texto oral pueden verse analizados por la crítica literaria y tanto uno como otro pueden resultar calificados como literarios o como coloquiales. Pero, en relación con su manera de exteriorizarse, el texto oral y el texto escrito quedan diferenciados de modo patente e inconfundible.

Finalmente, para poder juzgar y analizar con elemental conocimiento de causa el texto oral que ahora debemos contemplar, consideraremos dos diferentes aspectos. En primer lugar, señalaremos las características propias de lo oral frente a lo escrito, rasgos específicos de la oralidad (cf. V. Lamíquiz, 1989), marcas diferenciadoras que van a condicionar su estudio coherente. Y luego haremos mención de la innegable progresión que supone el paso de una sociedad de tradición oral hasta la sociedad de tradición escrita sin que, a nuestro juicio, una vez alcanzada la situación segunda, queden eliminados los rasgos fundamentalmente peculiares y valiosos de la primera.

\section{CARActeristicas del teXto oral}

Inicialmente, recordemos que el texto oral se propone como primordial finalidad satisfacer las fundamentales necesidades humanas de la intercomunica- 
ción, sencilla y diaria, en las imprescindibles relaciones sociales que son directas e inmediatas.

Paralelamente, la especificidad del texto oral radica en el hecho de su interlocución en presencia. El oyente u oyentes, receptores inmediatos, se encuentran en contacto humano directo con el hablante productor del texto. $Y$ ello origina un continuo autocontrol de la comunicación durante su misma realización. La directa experiencia contextual orienta de modo permanente el desarrollo comunicativo con la captación inmediata de las reacciones del interlocutor. Ello influye en la globalidad comunicativa donde, por una adecuada economía, aparecerán sustitutos gestuales de gran ahorro discursivo, silencios altamente informativos, interesantes y precisas matizaciones entonativas... que modificarán en fuerte contextualización los valores textuales denotativos. Aparecerá de manera clara y patente la pragmática, esa serie de datos que se presuponen en la interlocución y que aquí se verán perfectamente controlados en una inmediata experiencia tanto por el hablante como por el oyente $u$ oyentes.

En esa indiscutible inmediatez interlocutiva el texto oral se produce como espontáneo en un alto grado. La expresión comunicativa brota de una enunciación tan naturalmente propia del locutor que el resultado es un enunciado prácticamente desprovisto de premeditada manipulación formal.

Consecuencia del conjunto interrelacionado de esos rasgos específicos anotados es la variada diversidad que ofrece el producto discursivo oral. En la relación ineludible de la actuación enunciativa y su responsable que es el hablante, se distinguirá una gama gradual fundamentada en matices diastráticos. Así, la variedad diastrática a que nos referimos corresponderá al distinto nivel sociocultural de cada hablante, a su mentalidad, a su localización generacional al aire de tendencias ambientales de cada época sociohistórica, a su posición social subordinada incluso al sexo, hombre o mujer, en el grupo humano. Igualmente y de manera simultánea, el concreto enunciado discursivo resultante quedará condicionado y marcado por el hecho de la relación de la interlocución con la situación contextual. Se originará la serie diversa de registros textuales en la acomodación selectiva de cada momento comunicativo.

Por otra parte, la alta frecuencia de la práctica comunicativa en el intercambio humano supone que el texto oral sea inmensamente superior en orden cuantitativo a los textos escritos. Mas, el enunciado discursivo oral no deja de ser comunicación lingüística, por lo cual es bastante comprensible la atención que pueda o deba prestársele tanto desde una preocupación de consideración teórica como por razones prácticas de logrado empleo, hacia una mejora del uso común en mayor pertinencia y oportuna adecuación al logro de los objetivos puramente comunicativos. 
Al mismo tiempo, y posiblemente como consecuencia lógica palpable de su esencial razón de ser, el texto oral es efímero. Conocidísimo es el adagio verba volant, scripta manent. Sin embargo, a las palabras ya no se las lleva el viento puesto que hoy disponemos del vulgar magnetófono que nos permite conservar y mantener, con toda su exacta autenticidad, aquellos textos orales que, dentro de la gran cantidad de actuaciones enunciativas, nos interese conservar «en vivo» para una posterior observación empírica, fundamento esencial de todo trabajo científicamente serio.

Toda esta serie de rasgos peculiares de la oralidad contribuye a reafirmar la independiente personalidad discursiva que atribuimos al enunciado oral. Son marcas que deberán tenerse muy en cuenta llegado el momento de analizar los comportamientos específicos de la actualización linguíística hablada.

\section{DESDE LA SOCIEDAD DE TRADICIÓN ORAL...}

A fin de diferenciar la problemática en que se halla el hecho del texto oral, frente a la situación más conocida en que se estudia y analiza el texto escrito, juzgamos conveniente ampliar la perspectiva de sus condicionamientos respectivos. Así, para ello, distinguiremos las sociedades de tradición oral (cf. L. J. Calvet, 1984), que van desapareciendo en su estado puro al imponerse la culturización basada en el texto escrito pero que, sin embargo, permanecen en las sociedades de tradición escrita.

Una sociedad de tradición oral corresponde a la posición comunicativa primigenia del homo loquens (V. Lamíquiz, 1985a: 13). La adquisición de la capacidad de hablar, que hace del hombre un animal diferenciado superior, permite inicialmente el intercambio directo de sentimientos, de ideas y de conocimientos. Se trata de la finalidad práctica, primera manera de empleo del lenguaje.

En este tipo de sociedades la comunicación humana se ve, de manera simultánea, enriquecida con un doble apoyo comunicativo: un universo pictórico y un universo sonoro, ambos elementales al principio y, más tarde, en superación de perfeccionamiento progresivo.

Los mensajes pictóricos se manifiestan a través de formas propias que aparecen en los utensilios de uso común y habitual por perentorias necesidades instrumentales: en la cerámica de los recipientes para la comida, la bebida o el aseo; en los tejidos de la ropa para cubrir el cuerpo u organizar los habitáculos; en los avalorios con que se adornan y se embellecen las personas. 
Los mensajes sonoros vocales se potencian con los de los instrumentos musicales, inicialmente instrumentos de percusión que marcan un acompasado acompañamiento, productos de comunicación tan efímeros como la misma palabra oral.

Nos introducimos así en la finalidad imaginativa, segunda manera de emplear el lenguaje. En una comprensible, fácil y casi espontánea superación estética se alcanza la comunicación poética: el universo pictórico queda sublimado con la sugerencia de las imágenes simbólicas y el universo sonoro se plasma en su correspondiente ritmo e, incluso, en las rimas repetitivas de lo oral. Es el camino que conduce al nacimiento de la poesía popular oral.

La redundacia repetitiva del texto y el ritmo recitativo son elementos que sirven de base cómoda y adecuada para la memorización, modo de conservación de lo oral en su permanencia social y en la transmisión de estos mensajes dentro de esas sociedades de tradición oral: fábulas populares, cuentos romanceados y leyendas de contenido comunitario étnico y religioso.

Muestras de esta herencia oral se mantienen todavía hoy en nuestra sociedad avanzada. Y son documentables en todas las lenguas, especialmente en los estratos populares y preferentemente entre los niños. Baste recordar ciertos juegos infantiles donde el rítmico recitado de textos orales tradicionales, muy a menudo apoyados por música cancionil, va unido a la expresión corporal, por ejemplo saltando acompasadamente a la comba o caminando a pata coja sobre un esquema de casillas trazado sobre el suelo...

Y, como ejemplo fuertemente representativo de esta patente expresión conjunta de lo oral mantenido y de lo escrito añadido, contémplense estas características de comunicación semiótica que aparecen hoy día en cualquier manifestación callejera de protesta social o sindical. Ahí encontramos: un texto oral que recita y repite la masa de manifestantes, generalmente con pares semánticos, aliteraciones y rimas fáciles y pegadizas; un ritmo binario favorecido por la obligada acomodación al paso corporal de la marcha; un apoyo pictórico, más o menos rudimentario pero casi siempre bastante logrado, en las pancartas que se enarbolan en llamativa exhibición. No es preciso señalar que en ese conjunto se ven concentradas las tres finalidades: la finalidad práctica o consecución de una concreta reivindicación; la finalidad imaginativa en la manera atrayente de presentar la demanda social o sindical; y la finalidad didáctica en el propósito de los manifestantes de informar y de convencer a todo el grupo comunitario y conseguir una plena adhesión a la demanda reivindicada. 
Y añadamos la finalidad didáctica, que acabamos de observar, tercera manera de emplear el lenguaje en esas sociedades de tradición oral. En esta línea mencionaremos, entre otros conocidos recursos, los trabalenguas y las adivinanzas junto a las triquiñuelas y los versos disparatados, así como los dichos populares y los refranes.

Los trabalenguas son productos lingüísticos de la tradición oral que se fundamentan en un conocimiento fino de la fonología de la lengua. Muchos de ellos funcionan en conformidad con la regla de contraste mínimo según la cual los fonemas estrechamente relacionados por sus marcas respectivas no pueden oponerse dentro del marco de la misma palabra. Constituyen una iniciación a las dificultades fonémicas de la lengua con el propósito didáctico de desarrollar más concienzudamente una linguiística intuitiva. Así, por ejemplo, recordemos entre tantos

«Pablito clavó un clavo, un clavo clavó Pablito.»

con la variante

«Pablito clavó un clavito

¿qué clavito clavó Pablito?»

O bien,

«El cielo está enladrillado ¿quién lo desenladrillará?

El desenladrillador que lo desenladrille, buen desenladrillador será.»

O el similar

«Por el río bajan

tres tablas tarabincuntinculadas.

El carpintero que las tarabincunticulo, que las vuelva a tarabincuntincular.» 
$O$, igualmente, para mostrar la correcta realización en español del sonido ápico alveolar vibrante,
«Debajo un carro
había un perro
vino otro perro
y le mordió el rabo.
¡Pobre perrito! ¡Cómo corría
por la carretera arriba!»

Son textos bastante anodinos, con inevitables variantes por su transmisión oral memorizada, en los que es frecuente la situación pragmática en la que, cuando a causa de un error cambia el sentido de la palabra, la nueva significación resultante origina un valor tabú, casi siempre de orden sexual. Citemos el caso bien conocido de

«Del coro al caño

del caño al coro»

conjunto lingüístico con que los niños se divierten en una pugna o concurso de veloz pronunciación en realización fonémica repetidamente redundante.

En la vía didáctica de ejercicios prácticos de combinatoria distribucional de elementos lingüísticos, ya en relación con la composición léxica y sintáctica, aparecen las adivinanzas, del tipo

«Oro no es,

plata-no es.

¿Qué es?»

Evidentemente, no faltan en estos acertijos las susodichas sugerencias de inocentes picardías infantiles, como en

«A caballo te me pongo,

con el gusto te meneas,

yo con el gusto me voy

y tú con la leche te quedas" 
que queda limpiamente aclarada al precisar que se trata de... «la higuera».

Al lado de esta tradición oral para la adquisición de las destrezas correspondientes a la expresión semiolingüística, se afianza asimismo la orientación mental del raciocinio popular y de la reflexión coherente, aspectos que conciernen al contenido lingüístico. A ello contribuyen las triquiñuelas, así en

«Dos padres y dos hijos comen tres manzanas;

a cada uno le toca una manzana.»

que el pueblo, incluso los niños, alcanzan a resolver señalando que se comen una manzana... «el abuelo, el padre y el hijo».

Muy próximos se hallan los versos disparatados que igualmente persiguen formar la coherencia mental por medio de lo absurdo. Muchos recordarán de la niñez, quizá con la ayuda del ritmo musical acompañante, la cantinela romanceada
«Al salir de los cuarteles
con hambre de tres semanas,
me encontré con un ciruelo
cargadito de manzanas.
Empecé a tirarle piedras
y caían avellanas.
Con el ruido de las nueces
salí́ el amo del peral.
¡Chiquillo, no tires piedras
que no es tuyo el melonar.
Si me rompes un pepino,
me lo tienes que pagar!»

Por otra parte, la transmisión social educativa de los conocimientos prácticos del vivir diario se plasma por esta vía oral en los dichos, así en

\footnotetext{
«Recoger velas»

"Comer más que una lima»

«Marcharse a la francesa»
} 
y en tantas otras expresiones que, a través de sencillos símiles de imagen conocida en la experiencia, comunican pragmáticos saberes populares.

Los refranes, por su parte, son más sentenciosos y mantenidos en cierta tradición oral clásica. Muchos de ellos se refieren al tiempo climático, fundamental en un ambiente rural y agrícola por sus consecuencias en las cosechas:

«Año de nieves, año de bienes»

y tantísimos otros que cualquiera puede recuerdar.

$Y$ otras veces comunican la madura experiencia de la vida:

«Cuando las barbas de tu vecino veas pelar,

pon las tuyas a remojarm

o en otros muchos bien conocidos, llenos de sabiduría popular.

En fin, no cabe la menor duda de que, en esta extensa variedad de construcciones memorizadas en la tradición oral (cf. reseña de E. Martinell, 1989), nos encontramos ante una auténtica linguiústica aplicada donde la tradición oral opera con un gran poder pedagógico; por una parte, para una correcta adquisición de oportunas destrezas en el uso del lenguaje y, por otro lado, hacia una formación humana y social de los niños. De ahí su útil aprovechamiento en la didáctica de los primeros años escolares.

\section{5. ... HASTA LA SOCIEDAD DE TRADICIÓN ESCRITA}

La escritura se inventa para satisfacer necesidades prácticas sociocomunicativas: desde la administración de comerciantes en pedidos y facturas a distancia hasta la redacción de contratos. Y, aprovechada por los poderes públicos, es de gran idoneidad para la elaboración de normas de convivencia social y de códigos legales. Efectivamente, el texto escrito ofrece la ventaja de poder verse corregido, modificado o manipulado, según conveniencias comunicativas, antes de ser propuesto a los interlocutores. 
Más tarde, la escritura adquiere un fin intelectual con la posibilidad de su relectura reflexiva. Y, posteriormente, aparecerá su aprovechamiento para lo literario.

La invención de la imprenta, con la correspondiente facilidad de divulgación que supone para el texto escrito, propiciará el afianzamiento de la sociedad de tradición escrita.

Sin embargo, es importante observar que la instalación de la sociedad de la escritura no supone una completa sustitución de tipo de sociedad. Es decir, no se da la supresión de la sociedad de tradición oral por la sociedad de tradición escrita sino que ambas permanecen en una inseparable coexistencia.

Esta permanencia de la cultura oral en simultaneidad con la cultura escrita se manifiesta actualmente en el auge de la radio, al lado de la generalización de la televisión, resultados auténticamente representativos de esta mezcla, como medios potentes de comunicación. Porque la radio y la televisión no son una representación de la realidad sino que son la realidad misma, aspecto que atrae poderosamente en una cultura social que, aunque oficialmente escrita, no ha dejado de mantenerse en alto grado en la oralidad.

En lo referente al apoyo justificativo respecto a la veracidad comunicativa y a su rigor objetivo, en lo oral es preponderante el criterio genealógico, fundamentado en la memoria de la tradición: «solía decir mi abuelo», "contaba mi padre», «lo ha dicho mi hija»... Mientras que en lo escrito prima el criterio bibliográfico, en función de la autoridad concedida a los libros que se citen. En la tradición escrita se impone la cita llamada «textual», entrecomillada y con fiel respeto al estilo del autor. En cambio, en la tradición oral adquiere valor propio la memoria del locutor con su peculiar modo, improvisado o espontáneo, de recordar o de contar.

Porque en lo oral se valora la fuerza de la palabra con la garantía de la memoria. Sin embargo, en lo escrito es la fuerza del texto, fundamentada en la autoridad del autor del libro impreso. En la coexistencia de los dos tipos de sociedad se da el apoyo mutuo, detalle bien sabido y aprovechado por los poderes ideológicos de la religión: por ejemplo, la Biblia, el Corán o el Catecismo son textos escritos de permanencia social y contenido inmodificable que, no obstante, deben reiterarse en lectura y ser repetidos en la oralidad de la memoria.

\section{BASES DOCUMENTALES DE LO ORAL}

En un interés de descripción lingüística, los filólogos y los lingüistas se han preocupado con constancia por la captación directa de la oralidad de los hablantes en un paciente trabajo de campo. 
El quehacer dialectológico se desarrolló por áreas diatópicas esencialmente rurales, con una especial preocupación positivista por el hallazgo de curiosos elementos léxicos y por su peculiar realización fonética. Posteriormente, la pauta de cuestionarios previamente elaborados se ha visto con cierto apriorismo, a causa de su encauce hacia la observación de fenómenos preseleccionados, que deja fuera de estudio otros hechos lingüísticos que podrían ser pertinentes.

Con el fin de colmar estas y otras insatisfacciones investigadoras, nació la sociolinguística que fundamenta su observación en el comportamiento lingüístico de los hablantes de grupos humanos, especialmente en las grandes aglomeraciones de los núcleos urbanos (cf. V. Lamíquiz-P. Carbonero, 1987), interrelación linguuística y social manifiesta en el habla viva y directa. La documentación oral empírica que se obtiene, permite el análisis de cualquier aspecto del enunciado comunicativo: su fonética, su léxico, su sintaxis, su estructura fraseológica y textual; $y$, asimismo, detalles referentes al proceso de la enunciación.

La recogida de esta documentación se inicia con una correcta selección de informantes a fin de que el correspondiente muestreo ofrezca una alta representatividad del conjunto de hablantes. La información lingüística que resulte, queda de antemano equilibrada diastráticamente al diferenciar niveles socioculturales, generacionales y de sexo. El grupo porcentual de informantes, elegidos como muestra, abarcará adecuadamente la totalidad en elevado grado de garantía representativa.

Al mismo tiempo cuida la autenticidad del corpus textual que va a reunir como base documental. Para ello, protege estratégicamente de manera expresa la espontaneidad de los hablantes seleccionados para la muestra. Y, con esta metodología, recoge en vivo extensos retazos de discurso directo que graba en cintas magnetofónicas para su detenido y completo estudio posterior.

No se puede negar que la elaboración de un corpus documental oral que sea válido y aceptable, exige un trabajo delicado e ímprobo. Nuestra experiencia nos confirma la necesidad de una atenta y cuidadosa selección de informantes representativos, atinando con un genuino muestreo en rigor de adecuación sociolingüística; una paciente grabación de los textos conversacionales, amplios y abiertos, con oportuna astucia encuestadora para lograr la imprescindible espontaneidad en el informante; una juiciosa reconsideración de la encuesta grabada, en función de la idoneidad del texto enunciativo recogido, para admitirla o rechazarla en el corpus que se pretende; una fidelísima transcripción, con respeto absoluto al texto discursivo proporcionado por el hablante encuestado, cuidándose bien de cualquier interpretación subjetiva; una deseable informatización del texto documentado con el fin de aliviar en rápida 
automatización el largo trabajo manual de recuento de formas o de obtención de ocurrencias textuales, según interese en cada estudio posterior. Este trabajo escrupuloso y arduo en la elaboración de la documentación básica empírica asegurará la objetividad de los resultados que se analicen.

No es extraño que no abunden documentaciones provistas de estas laboriosas características. Destaquemos que el magno y ambicioso proyecto sobre el «Estudio de la norma lingüística culta del Habla de las grandes ciudades de España e Hispanoamérica» ha propiciado que, con una metodología coordinada, dispongamos hoy de una fiable documentación textual de enunciado oral, que es altamente valiosa y ofrece una gran garantía científica. Nos referimos a los textos de discurso enunciativo oral del español de las ciudades de México (J. M. Lope Blanch, coord. y otros, 1971); de Santiago de Chile (A. RabanalesL. Contreras, 1979); de Caracas (A. Rosenblat-M. T. Rojas, dirs. - P. Bentivoglio, coord., 1979); de Madrid (M. Esgueva-M. Cantarero, eds., 1981); de Sevilla (V. Lamíquiz, dir.- M. A. Pineda, ed., 1983 y además V. Lamíquiz, dir. - M. Ropero, ed., 1987); de San Juan de Puerto Rico (H. López Morales, coord., 1986); de Bogotá (H. Otálora de Fernández-G. A. González, eds., 1986); de Buenos Aires (A. M. Barrenechea, dir., 1987); de Lima (R. Caravedo, 1989).

Otro sistema de recopilación textual oral consiste en documentar «le tout venant»: todo texto oral que pueda captarse o grabarse en distintas y variadas situaciones contextuales. Es el método adoptado por el equipo de Aix-Marseille (G.A.R.S., Cl. Blanche-Benveniste, dir., 1983), a nuestro juicio la más seria investigación francesa sobre la lengua oral. O el empleado en otras investigaciones (por ejemplo, J. L. Román del Cerro, 1981). Aunque este sistema de documentación por muestreo de azar no asegura, en principio, la completa representatividad social del discurso linguístico recogido, sus datos no dejan de ser válidos siempre con la condición de que se aplique la consiguiente coherencia en el momento de proponer atribuciones generalizantes para los resultados del análisis.

Subrayemos el hecho de que todos estos textos, sea cual sea la intención inicial con que se hayan recogido, constituyen muestras específicas de enunciados orales. Se ofrecen para un análisis lingüístico en las diferentes facetas de lo fonético y fonológico, de lo lexemático, de lo sintáctico o de lo enunciativo.

\section{TENDENCIAS EN EL COMPORTAMIENTO LINGÜISTICO ORAL}

Nos parece oportuno señalar algunas tendencias de valor general en el comportamiento lingüístico del enunciado textual oral. Ello servirá para confirmar la independiente personalidad enunciativa de lo oral en relación con lo es- 
crito. El apoyo empírico de nuestras conclusiones se fundamentará en los textos orales que ofrece el corpus de documentación del Habla Culta de Sevilla (V. Lamíquiz, dir.- M. A. Pineda, ed., 1983).

El análisis del aspecto fonémico debe brotar de la experimentación a través de la audición fonética directa de las grabaciones. Ahí se nos ofrece un conjunto de realidades acústicas, inexistentes en el texto escrito transmitido por el sustitutivo grafémico. La captación de la variada y genuina oralidad lingüística, frente a la extensa uniformidad aparente de los textos escritos, nos permite diferenciar con pertinencia los grupos humanos de la diatopía, al mismo tiempo que nos asegura la sintomática coincidencia de preferencias uniformadas en los compactos grupos diastráticos. Y podrán precisarse con garantía los rasgos prestigiados frente a las características de realización fonética estigmatizadas en función del grado de aceptación social de unos u otras (V. Lamíquiz - P. Carbonero, 1987: 27-48).

En cuanto al uso sintáctico debemos subrayar la sencillez del texto oral. Puede originar una tendencia de simplificación de formas sistémicas frente a su mantenimiento conservador, a veces arcaizante, del texto escrito (V. Lamíquiz, 1985b: 105-120).

En el plano teórico, apoyado por el empleo que se analiza, debemos señalar la fuerte interrelación funcional entre lo que corresponde a la pura lexemática y lo perteneciente al dominio sintáctico, dificilmente separables. Porque se advierte una interesante selección en la construcción sintáctica que muestra el oportuno autocontrol tendente a eliminar las posibles ambigüedades interpretativas en el enunciado comunicativo. En esta línea se comprueba la hipótesis de que toda sinonimia lexemática queda destruida y resuelta en el enunciado textual por el conjunto actancial de presencia obligada en el discurso (V. Lamíquiz, 1992: 106-114).

En lo referente al empleo lexemático vamos a detenernos en mayor detalle. Puesto que conocemos el Diccionario de la Lengua o, mejor dicho, imaginamos conocerlo, se da la creencia de que en un texto discursivo se van a encontrar las unidades lexemáticas en él atesoradas, lo cual es cierto; y que se van a encontrar en igualdad de oportunidades, lo cual ya no es tan seguro pues dependerá del hecho comunicativo-informativo: todo texto presenta una determinada orientación de contenido comunicativo y, en consecuencia, una selección de léxico sesgada por el foco informativo. De aquí que la elaboración de una estadística léxica proporciona unos datos objetivos de justificada validez pero no de generalización lingüística aplicable por sí misma. Esta observación es de mayor importancia en lo que respecta a las unidades lexemáticas que se presentun en el enunciado con la categoría de sustantivo o de adjetivo. 
Refiriéndonos a las unidades lexemáticas en categoría sintáctica de verbo, seremos más explícitos. Para ello vamos a contemplar los verbos de uso común en nuestro banco de datos de texto oral: son unidades lexemáticas verbales que se hallan empleadas por todos los grupos diastráticos de informantes. Y contrastaremos su rango frecuencial de aparición con el que proporciona para esas mismas unidades el texto escrito, según datos que brotan de una estadística que ofrece toda garantía (A. Juilland-E. Chang Rodríguez, 1964).

Tenemos que distinguir cuatro grupos:

a) En primer lugar localizamos 36 verbos lexemáticos de uso común en el enunciado oral que coinciden con los 36 primeros verbos de mayor frecuencia de uso en lo escrito. Estas unidades son:

$\begin{array}{llll}\text { conocer } & \text { hablar } & \text { pensar } & \text { tener } \\ \text { creer } & \text { hacer } & \text { poder } & \text { tomar } \\ \text { dar } & \text { ir } & \text { poner } & \text { venir } \\ \text { deber } & \text { llamar } & \text { quedar } & \text { ver } \\ \text { decir } & \text { llegar } & \text { querer } & \text { vivir } \\ \text { dejar } & \text { llevar } & \text { saber } & \text { volver } \\ \text { encontrar } & \text { mirar } & \text { salir } & \\ \text { entrar } & \text { oír } & \text { seguir } & \\ \text { estar } & \text { parecer } & \text { sentir } & \\ \text { haber } & \text { pasar } & \text { ser } & \\ \end{array}$

Al coincidir en uso común en el enunciado oral y uso de mayor frecuencia en el escrito dentro de los 164 primeros rangos, podemos pensar que estamos ante las unidades lexemáticas verbales más empleadas por los usuarios de la lengua española.

b) En segundo lugar entresacamos otro lote de once verbos lexemáticos que aparecen todos ellos en el uso común de lo oral y se sitúan en el texto escrito entre los rangos 165 y 350 , o sea inmediatamente después de las unidades contempladas en el subgrupo primero. Se trata de los verbos siguientes:

$\begin{array}{llll}\text { comprender } & \text { existir } & \text { perder } & \text { servir } \\ \text { empezar } & \text { gustar } & \text { preguntar } & \text { tratar } \\ \text { estudiar } & \text { leer } & \text { recordar } & \end{array}$


c) El tercer subgrupo comprende una serie de verbos lexemáticos que en el enunciado escrito aparecen entremezclados con los del subgrupo anterior, igualmente entre los rangos 165 y 350 , pero no se documentan como de uso común en nuestra documentación de enunciado oral. $Y$ son:

$\begin{array}{llll}\text { abrir } & \text { comenzar } & \text { formar } & \text { presentar } \\ \text { acabar } & \text { considerar } & \text { hallar } & \text { producir } \\ \text { andar } & \text { contar } & \text { morir } & \text { recibir } \\ \text { aparecer } & \text { escribir } & \text { necesitar } & \text { referir } \\ \text { buscar } & \text { esperar } & \text { ocurrir } & \text { traer } \\ \text { caer } & \text { explicar } & \text { ofrecer } & \\ \text { callar } & \text { faltar } & \text { pedir } & \end{array}$

Con cierta coherencia, ante su alto rango frecuencial en lo escrito y al no ser de empleo común en lo oral, podríamos deducir que este tercer subgrupo responde a un comportamiento específico más propio del enunciado escrito.

En este criterio no deja de ser comprobatorio el observar las respectivas preferencias en el uso de una $u$ otra modalidad de enunciado:

comenzar en lo escrito frente a empezar en lo oral

$\begin{array}{lll}\text { hallar } & \text { encontrar } \\ \text { acabar } & \text { terminar } \\ \text { escribir } & \text { " } & \text { hablar }\end{array}$

siendo bien sintomático el último par en contraste.

d) Finalmente, señalamos en un cuarto subgrupo las unidades lexemáticas verbo que se presentan en ocurrencias discursivas de lo oral con un empleo común pero que, en el enunciado escrito, aparecen en rangos frecuenciales bastante o muy alejados. Estos verbos son:

\begin{tabular}{|c|c|c|c|}
\hline acordarse & mientras que en lo escri & ango & 1.043 \\
\hline caber & $\ll$ & $\ll$ & 869 \\
\hline cansar & $\ll$ & $\ll$ & 1.413 \\
\hline coger & $\ll$ & « & 860 \\
\hline dedicar & $\ll$ & $\ll$ & 824 \\
\hline interesar & $\ll$ & $\ll$ & 562 \\
\hline merecer & $\ll$ & $\ll$ & 656 \\
\hline sacar & « & $\ll$ & 389 \\
\hline terminar & $\ll$ & $\ll$ & 450 \\
\hline
\end{tabular}


Con idéntico razonamiento al adoptado anteriormente, sería ahora igualmente coherente considerar este cuarto subgrupo de unidades lexemáticas como más propias del enunciado oral frente al escrito.

Basten estas breves referencias acerca de peculiaridades fonéticas, comportamientos gramaticales y preferencias léxicas, propias del comportamiento linguístico del enunciado oral frente al texto escrito.

\section{ESTRUCTURAS FORMALES DEL DISCURSO ENUNCIATIVO.}

Donde las diferencias entre el texto escrito y el texto oral se manifiestan de manera más peculiar es en su respectiva arquitectura discursiva.

El enunciado textual escrito ofrece, por lo general, una construcción que podríamos calificar como lineal ascendente: se van sucediendo los razonamientos con gran carácter sumativo hasta alcanzar la cumbre del punto final. En cambio, el enunciado oral queda construido en una circularidad integrado$r a$ : la interlocución en presencia, que anteriormente hemos mencionado como rasgo de la oralidad, obliga al hablante a una permanente acomodación según sea el grado de captación interpretativa que observa directamente en el oyente; los focos informativos van enriqueciéndose y completándose al compás de la necesidad que se percibe; lo que se va diciendo se integra en lo ya dicho, de modo que, al concluir la comunicación, la información es globalizadora y totalizante. Esto origina repeticiones redundantes que suponen un autocontrol de insistente acomodación ante la reacción del oyente. En suma, la finalidad del hablante no está en la elegante forma sino en la pura y simple comunicación informativa que se pretende sea aprehendida por el oyente en sus oportunos y justos términos.

Otro rasgo llamativo de la arquitectura discursiva del enunciado oral es la marcada preferencia por una organización dialéctica, procedente de una argumentación en forma de alternativa comparativa en contraposición informativa. Esta dialéctica se apoya pragmáticamente en la experiencia común de los interlocutores. Así, por ejemplo, en nuestro banco de documentación empírica, si se pregunta por el clima, el interlocutor contrapone el buen tiempo con sol frente a la mala humedad; si se cuestiona sobre los toros, el hablante hará la alternativa entre los toros y el fútbol; si se habla de un coche, se hará el contraste entre marcas y modelos diferentes; si se pregunta por la vida en el campo, se contraponen el campo y la ciudad. Estas alternativas frecuentemente conducen al em- 
pleo de símiles o comparaciones con imágenes del mundo de la inmediata experiencia, a veces con evidentes logros expresivos.

Cuando contemplamos con detenida atención y curiosidad amplios retazos enunciativos del texto oral, nos encontramos con unos peculiares conjuntos discursivos que responden a claros esquemas bien trazados y con un interesante diseño de disposición frástica: son las configuraciones simétricas, logradas y consistentes construcciones especulares. No son excepcionales (V. Lamíquiz, 1988: 457-467) pues se encuentran con relativa facilidad en todo tipo de hablantes. Pero aquí sólo propondremos, como caso ejemplificador, una de ellas que hallamos en nuestra documentación (V. Lamíquiz, dir.-M. A. Pineda, ed., 1983: 292) en boca de una señora de 48 años que habla con entusiasmo de la Semana Santa sevillana. A la pregunta del encuestador que le insinúa eso?

-Mucha gente dice que las Vírgenes son todas iguales. ¿Tú crees

la hablante responde:

-No, hombre, eso lo tiene que decir uno que no sea de aquí, ¿no? Porque es como si dices... todos los chinitos son iguales, ¿no?, porque no se conocen, ¿no? Pero eso, claro, los que sean de fuera pues las ven todas arregladas poco más o menos lo mismo, bajo palio pues todas parecen la misma, ¿no? Ahora, claro, los Cristos los distinguen porque uno va crucificado, otro va con la cruz a cuestas, por eso se distinguen, ¿no? Pero la Virgen, como todas llevan la misma postura, ino?, por eso parecen la misma. Pero el que sea de aquí, que las conozca, vamos, las distingue en todo.

Esta respuesta ha quedado plasmada en una ordenación especular o simétrica que, si no nos constara su absoluta espontaneidad, diríamos que responde a un diseño previo y detenidamente pensado, conscientemente preparado y regulado. Pues la sucesividad discursiva lineal, sin ninguna modificación por nuestra parte, con completo y absoluto respeto al enunciado de la hablante, nos ofrece el siguiente esquema de simetrías: 


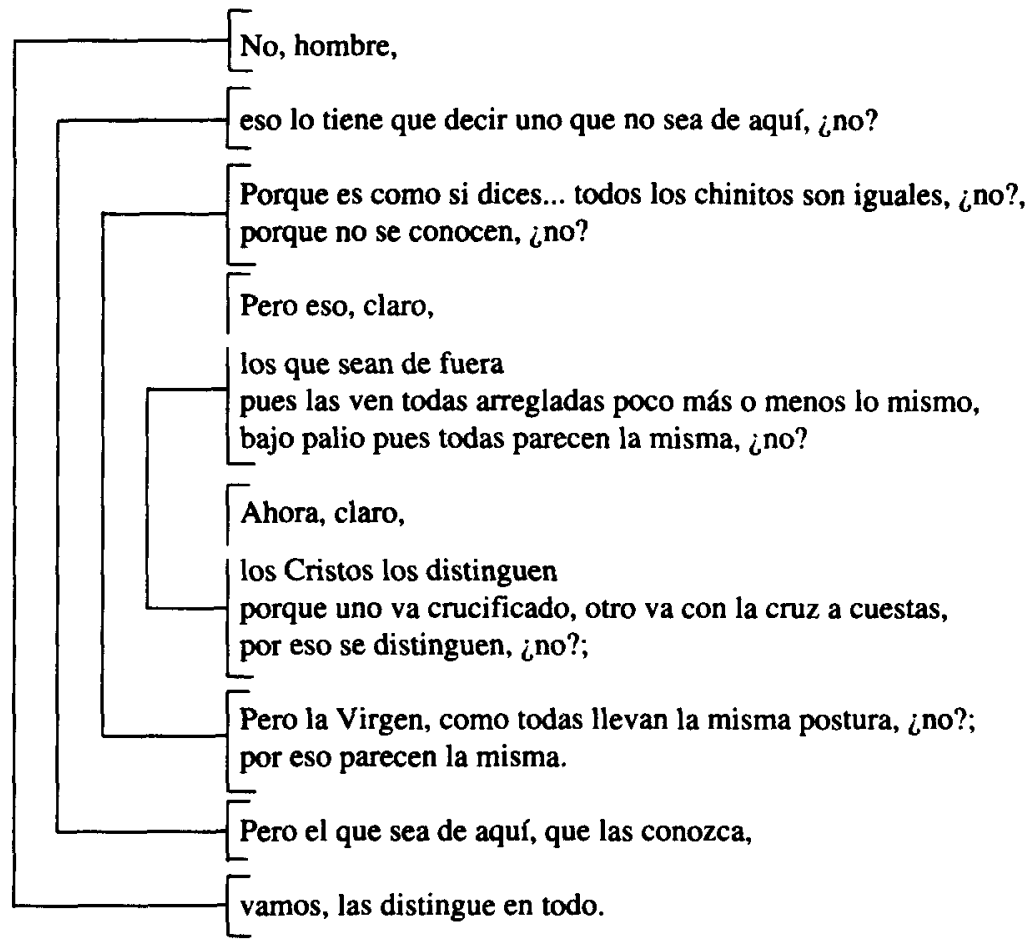

El resultado es manifiesto. Se habrán advertido bastantes de las características arriba anotadas: la disposición enunciativa circular y globalizante; la necesaria redundancia; la argumentación dialéctica que se instala al contrastar las Vírgenes de la pregunta con los Cristos que se añaden en la respuesta; el encantador símil de los chinitos; el valor discursivo que desempeña la forma interlocutiva ¿no?, prueba de autocontrol para percatarse de la captación comprensiva del oyente, y claramente situada como neta indicación de «cierre de bloque" expositivo, de mucha mayor transcendencia que una simple y condenable muletilla...

Estas configuraciones simétricas se encuentran también en otras lenguas (así, en francés, Cl. Blanche-Benveniste, 1985: 23) pero igualmente siempre como construcciones configurativas propias del enunciado oral. Inexistentes en los textos escritos en prosa, sin embargo se documentan asimismo en el discurso poético y, a veces, de manera extraordinariamente patente, como ha sido 
subrayado (R. Lapesa, 1985: 99) en la observación de la disposición versal y estrófica de la Égloga II de Garcilaso, lo que confirma nuevamente la proximidad de los enunciados orales con los poéticos escritos.

En definitiva, sirvan estas anotaciones y sugerencias acerca de rasgos no triviales que la curiosa observación puede hallar en el enunciado discursivo de la comunicación oral para percatarnos de la personalidad lingüística e interlocutiva del texto enunciativo directo oral. 


\section{BIBLIOGRAFÍA CITADA}

A.M. BARRENECHEA, dir. (1987), El habla culta de Buenos Aires. Materiales para su estudio. Buenos Aires, Instituto Amado Alonso, 2 tomos.

W. BEINHAUER (1978). El español coloquial. Madrid, Gredos, 3." ed.

Cl. BLANChE-Benveniste (1985), «Las regularidades configurativas en el discurso del francés hablado: consideraciones lingüísticas y sociolingüísticas» en V.Lamíquiz, dir. - F. R.-Izquierdo, ed.: Sociolingütstica andaluza 3. El discurso sociolingultstico. Sevilla, PUS, 19-30.

L. J. CAL Vet (1984), La tradition orale. Paris, PUF.

R. CaRAvedo (1989), El español de Lima. Materiales para el estudio del habla culta. Lima, Pontificia Universidad Católica del Perú.

M. Esgueva; M. CANTARERo, eds. (1981), El habla de la ciudad de Madrid. Materiales para su estudio. Madrid, CSIC.

G.A.R.S. (1983), Recherches sur le français parle, n..$^{\circ}$ 5. Aix-en-Provence, Université de Provence.

A. Juilland; E. Chang Rodríguez (1964), Frequency Dictionary of Spanish Words. The Hague, Mouton.

V. LAMfQUIZ (1985a), El contenido lingǘstico. Barcelona, Ariel.

V. LAMfQUIZ (1985b), «El sistema verbal idealizado y su comportamiento discursivo» en V.Lamiquiz, dir. - F. Rz Izquierdo, ed.: Sociolingǘstica andaluza 3. El discurso sociolingüŕstico. Sevilla, PUS, 105-120. 
V. Lamíuiz (1988), «Configuraciones discursivas en textos orales» en Hommage à Bernard Pottier. Paris, Klincksieck, vol. 2, 457-467.

V. LAmfouiz (1989), «Sobre el texto oral» en Philologica. Homenaje a A. Llorente. Salamanca, Universidad, II, 39-45.

V. LAMf́uIz (1992), «Lexemática aplicada en el discurso sociolingüístico» en Scripta Philologica in honorem Juan M. Lope Blanch. México, UNAM, 95-117.

V. LAMf́uIz, dir - M.A. PINEDA, ed. (1983), Sociolingǘistica andaluza 2. Encuestas del habla urbana de Sevilla. Nivel culto. Sevilla, PUS.

V. Lamiquiz; P. CARbonero (1987), Perfil sociolingüfstico del sevillano culto. Sevilla, Instituto de Desarrollo Regional.

V. LAMf́uiz, dir.; M. ROPERo, ed. (1987), Sociolingüistica andaluza 4. Encuestas del habla urbana de Sevilla. Nivel popular. Sevilla, PUS.

R. LAPESA (1985), Garcilaso. Estudios completos. Madrid, Istmo.

J. M. LoPE BLANCH, coord. y otros (1971), El habla de la ciudad de México. Materiales para su estudio. México, UNAM.

H. LOPEZ MORAles, coord. (1986), El habla de San Juan de Puerto Rico. Materiales para su estudio. San Juan, Universidad de Río Piedras.

E. MarTinell (1989), «Diversos números de la colección Nueva Castilla». Reseña en REL, 19-2, 485-487.

A. NARBona (1986), «Problemas de sintaxis coloquial andaluza» en $R E L, 16-2,229$ 775.

A. NARBONa (1988), «Sintaxis coloquial: problemas y métodos» en $L E A, \mathrm{X}-1,81-106$.

A. Narbona (1989), Sintaxis española: nuevos y viejos enfoques. Barcelona, Ariel Lingürstica.

H. Otalora de Fernandez; G.A. GonzÁlez, eds. (1986), El habla culta de Bogotá. Materiales para su estudio. Bogotá, Instituto Caro y Cuervo. 
A. Rabanales; L. Contreras, coords. (1979), El habla culta de Santiago de Chile. Materiales para su estudio. Santiago de Chile, anejo del BFSCh.

A. Rosenblat; M.T. Rojas, dirs.; P. Bentivoglo, coord. (1979), El habla culta de Caracas. Materiales para su estudio. Caracas, Universidad Central de Venezuela.

ReAl ACADEMIa Española (1984), Diccionario de la lengua española. Madrid, Espasa-Calpe, 2 tomos.

J.L. ROMÁN DEL CERRO (1981), El léxico base del castellano: análisis estadístico y de contenido. Alicante, Caja de Ahorros Provincial.

R. SenABre (1992), «Lengua coloquial y lengua literaria» en Fundación Juan March. Boletín Informativo 221, 3-14.

A. M." Vigara Tauste (1992), Morfosintaxis del español coloquial. Esbozo estilístico. Madrid, Gredos. 